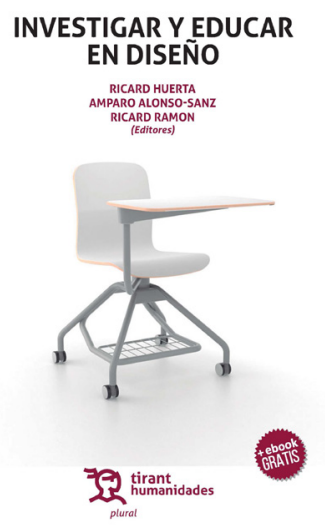

Investigar y educar en diseño

Ricard Huerta, Amparo Alonso-Sanz y Ricard Ramon (Coords.)

Año: 2018 Lugar: València

Editorial: Tirant lo Blanch

Páginas: 213

ISBN: 9788417203894

\title{
El diseño como herramienta de transformación social
}

Las artes aplicadas han hecho posible la presencia del arte en la vida cotidiana, a la vez que han tenido desde su origen una vinculación con la contemporaneidad y la innovación tecnológica. El desarrollo tecnológico ha propiciado el surgimiento de nuevos materiales, de nuevos usos que redefinen la misma idea de funcionalidad en el diseño, y de nuevos lenguajes derivados de la interactividad e hipertextualidad, que erosionan los tradicionales lindes entre las disciplinas artísticas. Por otra parte, la crisis del paradigma de la modernidad ha conducido a nuevas prácticas del diseño, entendido como instrumento de transformación social.

Junto a la función comunicativa y educativa, el diseño se convierte de este modo en un medioidóneoparareplantearsecuestionescomoeldesarrollohumano, lasostenibilidad y la construcción de nuevos discursos y posicionamientos culturales y vitales.

En este contexto, el libro Investigar y educar en diseño, coordinado por los profesores Ricard Huerta, Amparo Alonso-Sanz y Ricard Ramon, se enmarca dentro de las investigaciones y acciones desarrolladas por el Grupo de Investigación en Pedagogías Culturales CREARI (GIUV2013-103), ofreciéndonos una selección de textos que nos invitan a reflexionar sobre estas cuestiones.

Estas acciones tuvieron su arranque con la celebración en Valencia, en noviembre de 2017, de las VIII Jornadas Internacionales de Investigación en Educación Artística, promovidas por el Grupo CREARI, la Escuela de Arte y Superior de Diseño de València y el Instituto de Creatividad e Innovaciones Educativas de la Universitat de València, con la colaboración de Las Naves Centre d'Innovació (Ajuntament de València); y la publicación del dossier Investigar y educar en diseño, presentado en el número 8 de la revista EARI en dichas jornadas, a través de las que se reivindicaba la importancia de la investigación en el campo del diseño y de la visibilidad de su situación académica. 
Estas reflexiones y contribuciones tienen su continuidad en los textos del presente volumen. El libro ofrece un amplio panorama de ideas y opiniones que parten de la convicción de que diseñar es investigar, es encontrar soluciones a problemas nuevos o replantearse nuevas preguntas, partiendo de la base que educar es la clave para construir una ciudadanía consciente. En el volumen encontramos iniciativas que van desde el estudio de la tipografía (Ricard Huerta) y su papel destacado en el diseño del libro (Juliana Javaloy), al diseño industrial (Yolanda Lifante). Desde el diseño de los espacios educativos (Amparo Alonso-Sanz), y las enseñanzas del diseño en el contexto de la educación secundaria (Ismael Lozano), hasta las experiencias llevadas a cabo en las escuelas de diseño (Vivián Fernández, Anna Majó y Octavi Rofes). Encontramos también miradas autobiográficas desde la profesión del diseñador (Vicent Martínez), y como medio de pensamiento y construcción del conocimiento autónomo (Ricard Ramon) o de investigación (Xavier Giner). Por último, otros textos nos acercan a los puntos de confluencia entre el museo y el diseño (Raquel Cacho, Sela del Pozo, Sofía Rodríguez e Isabel Rodríguez), con las tecnologías (David Mascarell), o con las prácticas artísticas contemporáneas (María Vidagañ).

Los lectores de este libro, podrán en definitiva a través de su lectura, encontrar una fecunda visión del diseño, que nos anticipa el valor destacado de éste como generador de dinámicas transformadoras de la sociedad.

Ricardo Domínguez. Universitat de València 